PAPER

\section{Medroxyprogesterone acetate or long-acting progesterone in the biostimulation of lambs}

\author{
Claudia D. Monteiro, Sony D. Bicudo, \\ Hugo S. Toma, Carmo E.A. Biscarde, \\ Tiago M. Oliveira, Marcel B. Falleiros, \\ Luana C. Bicudo, Luis C. O. Magalhães \\ Departamento de Reprodução Animal e \\ Radiologia Veterinária, Universidade \\ Estadual Paulista Julio de Mesquita Filho, \\ Botucatu, Brazil
}

\section{Abstract}

The aim of this study was to evaluate the response of prepubertal ewe lambs to exogenous administration of either medroxyprogesterone acetate (MAP) or long-acting progesterone (LAP) together with biostimulation. Two Pool Dorset adult males and 75 mixedbreed prepubertal ewe lambs (average of 179 days-old and $30.0 \mathrm{~kg}$ ) were used. The females were randomly assigned to three different groups. In the first group the females were submitted to the insertion of intravaginal sponges containing MAP (60 mg) for 12 days and were then biostimulated for eight weeks. In the second group the females were submitted to a single injection of LAP ( $225 \mathrm{mg}$ ) and then to biostimulation for eight weeks. In the last group, the females were only submitted to biostimulation for eight weeks. Animals were considered cyclic when plasma progesterone (P4) concentration exceeded $1.0 \mathrm{ng} / \mathrm{mL}$ in at least one of two consecutive blood samples taken within a 7-day interval in three distinct experimental moments. After treatments 93.3\% of the females disregarding their group started their cyclicity and most of them (92.0\%), continued to be cyclic after 63 days of either MAP or LAP together with biostimulation under both male and female effect. We conclude that prepubertal ewe lambs when submitted to protocols of either MAP or LAP followed by biostimulation result in puberty at the 7 month of age. It can be deducted that some ewe lambs submitted to the administration of either MAP or LAP together with biostimulation promoted a multiplier effect upon the other young females that were then stimulated to start cyclicity.

\section{Introduction}

The beginning of sexual activity for both males and females is very important when it comes to animal rearing, especially due to the profit gains that only begins when the animals return to the productive phase.

There are several definitions about the onset of puberty, including age at first oestrus, age at first ovulation, female age at which the supports without deleterious effects on future pregnancy, the latter mainly related to body weight. The age at puberty in ewe lambs is between 4 and 14 months (Senger, 1997).

During the first year of reproductive activity, the fertility of the ewe lambs is low if compared with the sheep (Senger, 1997). A series of signs show that the ewe lambs remain sexually immature for some time after they reach their puberty, and puberty here is defined as the time they present the occurrence of the first oestrus (Sasa et al., 2002). Immaturity is characterized by events that include short duration oestrus and low intensity of the oestrus signs (Sasa et al., 2002), as well as the presence of ovulation without oestrus signs and cycles that are either irregular or long ones (Bathaei, 1996).

The social relationship that an animal has with others of the same species and the effects generated by their presence is called biostimulation (Ungerfeld, 2003; Ungerfeld et al., 2003). Its role in the reproduction of many mammals such as rodents, swine, ovine and bovine is to anticipate sexual maturity, to induce ovulation, and to reduce the time of postpartum anoestrous (Roman et al., 2007). In ovine, this effect can be noticed in several group combinations such as male-male, female-female, male-female, and it occurs to all age combinations (Rosa and Bryant, 2002).

For the expression of the first oestral behaviour, it is necessary that the female is subjected to a previous exposure to certain plasmatic concentrations of progesterone that are originated by the corpus luteum formed after the first ovulations in the puberty period (Martin, 1992).

The association of the male effect with progestogens in synchronization treatments for sheep that are in anoestrous is as effective in the induction of ovulations as the ones that associate gonadotropins (Umberger et al., 1994).

In the intensive farming that aims at meat production, the male lambs are slaughtered soon after they wean. Young females according to their time of birth stay in the property being fed and handled until the mating season of the
Corresponding author: Dr. Claudia D. Monteiro, Departamento de Reprodução Animal e Radiologia Veterinária, Universidade Estadual Paulista Julio de Mesquita Filho, Botucatu, 18606-000, Brazil.

Tel. +55.14.38116249- Fax: +55.14 .38116249$

E-mail: claudiadiasmonteiro@hotmail.com

Key words: Ewe lambs, Biostimulation, MAP, Progesterone, Prepubertal period.

Acknowledgments: the authors thank Dr. Antonio Sérgio Villas Bôas for his support in the accomplishment of the present work, Dr. Alcides Amorim and Rodrigo Bittencourt for their help in the accomplishment and interpretation of the statistical data, Bethania Vieira Lopes and Fabíola Soares Zahn.

They also thank Capes Brazil and Fundunesp Brazil for the financial support.

Received for publication: 8 April 2010. Accepted for publication: 29 June 2010.

This work is licensed under a Creative Commons Attribution 3.0 License (by-nc 3.0).

CC Copyright C.D. Monteiro et al., 2010 Licensee PAGEPress, Italy

Italian Journal of Animal Science 2010; 9:e64 doi:10.4081/ijas.2010.e64

following year when they are then over 1 year of age, which represents an economical disadvantage for the farming system (Villas Bôas et al., 2003).

This study will consider the onset of puberty for the first ovulation.

The purpose of this study was to evaluate the response of prepubertal ewe lambs to the exogenous administration of either medroxyprogesterone acetate or long-acting progesterone associated to the biostimulation.

\section{Materials and methods}

\section{Management}

The experiment was carried out from the second semester of 2007 to the first semester of 2008 in the mating pre-season (November 2007 to February 2008) with meat mixed breed ovine ewes, in Arandú, Sao Paulo, Brazil (Latitude: $20^{\circ} 00^{\prime} \mathrm{S} /$ Longitude: $48^{\circ} 56^{\prime} \mathrm{W}$ ).

The animals were reared according to the following protocol (Villas Bôas et al., 2003)

- Supplementation of the lambs in the creepfeeding system from their birth to their weaning, with feed of $18.0 \%$ of raw protein 
and $78.0 \%$ of total digestible nutrients (NDT).

- Lambs were weaned at 62 days of age.

- After weaning, lambs were provided housing and ad libitum feed supplementation for 15 days with a diet of $14 \%$ of raw protein and $68.0 \%$ of NDT.

- After these 15 days of supplementation the ewe lambs were taken to paddocks of Panicum maximum (Aruana) in which they were kept until their adult life, with access to ad libitum mineral salt and water.

\section{Animals}

Two Pool Dorset adult males and 75 mixedbreed prepubertal ewe lambs were used, aged between 154 and 218 days, (average of 179 days and se \pm 1.2 days) and weighing between 25.8 and $36.9 \mathrm{~kg}$ (average of $30.0 \mathrm{~kg}$ and $\mathrm{SE} \pm 0.1 \mathrm{~kg}$ ) in the beginning of the experiment.

\section{Experimental groups}

The females were randomly assigned to three different groups. In all groups, the animals had similar bodyweight (BW), body condition score (BCS) and body mass index (BMI), and all animals (from all three groups) were kept in the same paddock for the whole experiment.

- Medroxyprogesterone acetate (MAP) group: females $(n=25)$ were submitted to the insertion of intravaginal sponge containing medroxyprogesterone (Progespon ${ }^{\circledR}$, Syntex S.A., Argentina - $60 \mathrm{mg}$ MAP) for 12 days (Godfrey et al., 1997) and were biostimulated for eight weeks to mimic a breeding season. - Long-acting progesterone (LAP) group: females $(n=25)$ were submitted to a single intramuscular injection of $1.5 \mathrm{~mL}$ of progesterone (225 mg) (LAP 4-150 oily vehicle) and were then biostimulated for eight weeks to mimic a breeding season.

- Biostimulated group: females $(n=25)$ were only subjected to biostimulation for eight weeks to mimic a breeding season.

\section{Experimental moments}

On day zero (D 0), sponges from MAP group animals were taken out and males were put into the paddock where they had contact with females from all three groups. Five days before that (D-5) LAP group animals received the single injection of long-acting progesterone.

Biometry involving BW, BCS and BMI and blood sampling was held in two different occasions with a 7-day interval from one another for the evaluation of the luteal functionality, and these measurements occurred in three different experimental moments (Shabankareh et al., 2009).

- Experimental moment 1 (M1): nineteen days before the beginning of the biostimulation (D-19).

- Experimental moment 2 (M2): seven days after the beginning of the biostimulation (D 7).

- Experimental moment 3 (M3): fifty-six days after the beginning of the biostimulation (D $56)$.

The experimental moments were performed in order to obtain parameters on the cyclicity of lambs before stimulation (M1), soon after the stimulations (M2) and to evaluate the continuity of cyclicity (M3). The experimental days were based on the placement of the males with the lambs, day zero (D0).

\section{Animal weighing}

Animals were individually weighed using a digital scale (Trutest ${ }^{\circledR}$ XR 3000, Farm Tech SA, Porto Alegre, Brazil), and data were expressed in kilograms $(\mathrm{Kg})$.

\section{Body mass index and body condi- tion score}

The corporal biometry was taken with the animal in normal standing position using a 1.0 meter-long instrument to check measures from height to withers (HW), and from the sternum (breast-bone) to the ischiatic tuberosity (SIL) (data expressed in centimetres). BW was expressed in kilograms (Kg) as mentioned before. BMI was calculated using the following equation: $\mathrm{BMI}=\mathrm{BW} \times \mathbf{x}[\mathrm{HW} \times$ $\left.100^{-1}\right) \times(\text { SIL x 100 } 10]^{-1}$ (Bicudo et al., 1995).

BCS measurement was taken by the same technician with the animals in their normal standing position using a range from 1 to 5 (Radostits et al., 1994).

\section{Progesterone radioimmunoassay}

Blood samples were collected in heparinized tubes from jugular venipuncture and kept under cooling until the moment that they were centrifuged at $1,200 \mathrm{xg}$ for $10 \mathrm{~min}$. Plasma was kept at $-30^{\circ} \mathrm{C}$ until progesterone levels were measured.

The plasmatic progesterone level wasdosed via radioimmunoassay (RIA) with $0.2 \mathrm{ng} / \mathrm{mL}$ of sensitivity in solid phase making use of commercial kits (DPC, Med Lab-Diagnostic Products Corp., Los Angeles, CA, USA) according to the manufacturer recommendations. Reading was done in a Beckman 5500 gamma counter. The intra-rehearsal assay was calculated starting from the insert of three repetitions in duplicates. The intra- and inter-assay coefficient of variation were $<10 \%$.

\section{Definitions}

The existence of luteal phases, which we assumed as a sign of cyclicity, was established according to blood progesterone concentration and it had to exceed $1.0 \mathrm{ng} / \mathrm{mL}$ in at least one of two consecutive blood samples taken within a 7-day interval (Shabankareh et al., 2009).

\section{Statistical analysis}

Data are presented through descriptive statistics, being the variables submitted to the variance analysis and compared by the Tukey test with $5 \%$ of probability at the SAS program System (Cochran and Cox, 1976).

For statistical analysis the values of plasmatic P4 levels were transformed in Log [ ] $\mathrm{P} 4+1$.

Data regarding the cyclicity of females were submitted to the chi-squared test with $5 \%$ of significance.

\section{Results}

Table 1 shows the following growth indicators: BW, BMI and BCS of prepubertal ewe lambs for all groups and in all experimental moments.

There was difference concerning BW and BMI among moments, with growing values in M1, M2 and M3, however, the mean value of

Table 1. Average BW, BMI and BCS (average \pm SE) in the experimental moments and groups of ewe lambs $(n=75)$ submitted to biostimulation and exogenous administration of either medroxyprogesterone acetate or long-acting progesterone.

\begin{tabular}{lcccccc}
\hline \multicolumn{3}{c}{ Moment } & \multicolumn{3}{c}{ Group } \\
& M1 & M2 & M3 & MAP & LAP & Biostimulated \\
\hline Indicator & & & & & & \\
BW & $30.00 \pm 0.51^{\mathrm{c}}$ & $32.46 \pm 0.40^{\mathrm{b}}$ & $34.37 \pm 0.44^{\mathrm{a}}$ & $32.64 \pm 0.41^{\mathrm{a}}$ & $32,98 \pm 0.37^{\mathrm{a}}$ & $31.87 \pm 0.33^{\mathrm{b}}$ \\
BMI & $80.97 \pm 0.04^{\mathrm{c}}$ & $86.19 \pm 0.10^{\mathrm{b}}$ & $95.76 \pm 0.19^{\mathrm{a}}$ & $86.55 \pm 0.47$ & $86.78 \pm 0.51$ & $86.22 \pm 0.44$ \\
BCS & $2.83 \pm 0.03$ & $2.76 \pm 0.01$ & $2.75 \pm 0.02$ & $2.79 \pm 0.02^{\mathrm{a}}$ & $2.76 \pm 0.02^{\mathrm{a}, \mathrm{b}}$ & $2.68 \pm 0.02^{\mathrm{b}}$ \\
\hline
\end{tabular}

Different letters in the line, in the group or in the moment indicate statistical difference, Tuckey, $\mathrm{P}<0,05$; M1, experimental moment 1- before stimulation; M2, experimental moment 2- shortly after stimulation; M3, experimental moment 3- to evaluate cyclicity. 
BMI was similar among groups. Animals from MAP and LAP groups presented higher BW in relation to the ones from exclusive biostimulation (Table1). BCS did not present any difference among the assessed moments but differed for MAP and Biostimulated groups (Table1).

The correlation between BCS and BMI was $20.5 \%(\mathrm{P}=0.0019)$ and it was low because there was an increase of BMI while BCS remained the same.

Table 2 presents the percentage of cyclic ewe lambs in the experimental moments. In M1 (D-19) all of the ewe lambs $(n=75)$ presented plasmatic values of progesterone lower than $1.0 \mathrm{ng} / \mathrm{mL}$ (means $0.12 \pm 0.01 \mathrm{ng} / \mathrm{mL}$ ) in the two consecutive samples taken 7 days apart, thus indicating that they did not display cyclic activity until the beginning of the experiment.

In M2 $93.3 \%$ of all ewe lambs $(n=75)$ presented either the same or $>1.0 \mathrm{ng} / \mathrm{mL}$ plasmatic values of progesterone (mean $4.15 \pm 0.80$ $\mathrm{ng} / \mathrm{mL}$ ) in at least one of the two consecutive samples taken 7 days apart. It was assumed that all three groups showed cyclic activity in this moment (MAP group 96.0\%, LAP group 92.0\%, Biostimulated group, 92.0\%) (Table 2).

As for M3, most (92.0\%) of the ewe lambs of the three groups presented plasmatic values $\geq 1.0 \mathrm{ng} / \mathrm{mL}$ (mean $3.86 \pm 0.92 \mathrm{ng} / \mathrm{mL}$ ) in at least one of the two consecutive samples taken 7 days apart (Table 2).

The percentage of cyclic ewe lambs in the $\mathrm{M} 2$ and $\mathrm{M} 3$ was higher than in $\mathrm{M} 1 \quad(\mathrm{P}<0.001)$ based on the plasmatic values of $\geq 1.0 \mathrm{ng} / \mathrm{mL}$ in the two consecutive samples taken 7 days apart. There was no difference in the cyclic activity between M2 and M3 ( $>0.05)$.

\section{Discussion}

Starting from the eighth week of life until puberty the gonadotropins secretion is suppressed by the negative retrograde control of the estradiol, and this occurs until the ewe lambs have both appropriate BW and metabolic state to reproduce (Rawlings et al., 2003).

During pre-puberty, there is a decrease in the concentration of receptors for estradiol in both hypothalamus and hypophysis, which allows the increase of LH pulses frequency and an increase in the estradiol production from the ovarian follicles with consequent development of the genitalia (Schillo et al., 1992).

The appropriate frequency and amount of GnRH secretion is the appropriate stimuli for gonadotropins liberation in the anterior lobe of

Table 2. Cyclic ewe lambs in experimental moments (M1, M2 and M3).

\begin{tabular}{lccc}
\hline & M1 & $\begin{array}{c}\text { Cyclic females }(\%) \\
\text { M2 }\end{array}$ & M3 \\
\hline Group & & & \\
MAP & $0(0 / 25)^{\mathrm{b}}$ & $96.0(24 / 25)^{\mathrm{a}}$ & $92.0(23 / 25)^{\mathrm{a}}$ \\
LAP & $0(0 / 25)^{\mathrm{b}}$ & $92.0(23 / 25)^{\mathrm{a}}$ & $92.0(23 / 25)^{\mathrm{a}}$ \\
Biostimulated & $0(0 / 25)^{\mathrm{b}}$ & $92.0(23 / 25)^{\mathrm{a}}$ & $92.0(23 / 25)^{\mathrm{a}}$ \\
Average & $0(0 / 75)^{\mathrm{b}}$ & $93.3(70 / 75)^{\mathrm{a}}$ & $92.0(69 / 75)^{\mathrm{a}}$ \\
\hline
\end{tabular}

Different letters in the line indicate statistical difference, $\mathrm{P}<0,05$; M1, experimental moment 1- before stimulation; M2, experimental moment 2- shortly after stimulation; M3, experimental moment 3 - to evaluate cyclicity.

the hypophysis. In the prepubertal phase, presynaptic neurons are unable to transmit information to the hipotalamous. Their function seems to be influenced by several factors such as: nutrition, exhibition to certain atmospheres, social relationships, genetics, and birth season, among others (Senger, 1997).

The beginning of the reproductive activity in the ovine is more frequently associated to the body development rather than to the chronological age (Bielli, 2000). The BW of the ewe lambs in $\mathrm{M} 2(32.46 \pm 0.40 \mathrm{Kg})$ was compatible with $2 / 3$ of the adult BW, as pointed out by Chappell (1993) to be the necessary event to trigger puberty.

Taking the animal breed and breeding into consideration, the BW of the ewe lambs at the end of the experiment (average age of 234 days old) was superior to the one found in the literature (Villarroel et al., 2006). All females presented the appropriate body development, which was needed to trigger puberty especially because they were subjected to the Villas Bôas et al. (2003) model that favours the ruminal development of the lambs. This provides further energy and protein supply since the maternal milk tends to decrease its nutritional values with the progress of the nursing.

The BW gain and ascending BMI curve along the experimental moments demonstrate that the ewe lambs of the three groups were in their growth phase. The establishment of the growth indicator and corporal status like BMI, based on the BW, withers height and sternalischiatic length brings accuracy to the evaluation of both population and individual body development. However, there is the need to determine the appropriate relationship between the BMI with the age of the onset of puberty in the future.

The evolution of the BCS of the ewe lambs did not present any increase, despite the variations among the groups. Although this indicator allows the evaluation of the corporal condition throughout the experiment, it does not correspond to the cyclicity of the females.

During the oestral cycle (17 days) the prog- esterone peak occurs on D 11, its level starts to decline on D13 and it reaches the lowest concentration on D16. Values of $\mathrm{P} 4<1.0 \mathrm{ng} / \mathrm{mL}$ were detected on cyclic females for 6 days maximum, between the last 3 days and the first 3 days of oestral cycle (Shabankareh et al., 2009). Then, two samples were taken 7 days apart, for the detection of $\mathrm{P}_{4}$ in order to determine the cyclicity through the evaluation of the luteal activity.

Sheep that are in anoestrous display a better response when they are induced to cyclicity after exogenous administration of MAP associated to the social effect (female-female, female-male) rather than the isolated biostimulation or the use of progestogens (Ungerfeld, 2003). In prepubertal goats, the presence of the buck seems to potentiate the effect of PMSG (91.6\%) and therefore constitute an important stimulus to induce the pubertal oestrus in does (Mellado et al., 2000).

In the present experiment the percentage of cyclic ewe lambs (92.0-96.0\%) was close to one obtained by Ungerfeld et al. (2003) with the MAP associated to biostimulation in sheep that were in anoestrous (97.7\%).

The ewe lambs became cyclic after exogenous administration of either medroxyprogesterone acetate or long-acting progesterone ( 0.0 vs. $96.0-92.0 \%)$.

According to Rosa and Bryant (2002), the previous exposure to $\mathrm{P} 4$ associated to biostimulation alters the estrogen response mechanisms in the pre-puberty phase which leads to a gradual increase of follicular growth, estrogen concentrations, LH peak and occurrence of ovulation.

The pre-puberty phase is affected by the length of the seasonal anoestrous of each breed. Consequently, the month of birth is a decisive factor at the onset of puberty (Moreno et al., 1999).

When ewe lambs are born in the beginning of the reproductive season, they will reach puberty earlier than the ones born at the end of the season that will present rut in the reproductive season of following year (Bathaei, 
1996). The ewe lambs that were born in the autumn lived the decreasing and increasing photoperiod successively and they reached appropriate BW $(32.46 \pm 0.40 \mathrm{Kg})$ in the spring mating pre-season with the age of $205 \pm 2.9$ days, which favoured the start and maintenance of the cyclicity. Being exposed to the males and the other cyclic ewe lambs (from MAP and LAP group) biostimulated group females began their reproductive activity due to the interference of the "female-female" and "male-female" effects.

The continuous presence of cyclic females or the sudden introduction of sheep in oestrus (usually induced by hormone injection) is capable of inducing and synchronizing ovulation among females, anticipating the beginning of their reproductive season (Zarco et al., 1995; Mobini, 2002).

In this experiment, the biostimulation was applied in association with either progestogens or progesterone, which provides a substantial reduction of costs on hormones (Evans et al., 2004).

\section{Conclusions}

We conclude that prepubertal meat mixedbreed ewe lambs when submitted to protocols of either $60 \mathrm{mg}$ of medroxyprogesterone acetate administered for 12 days via intravaginal sponge or $225 \mathrm{mg}$ of oily long-acting progesterone followed by biostimulation result in puberty at the 7 month of age in the mating pre-season. In addition, this could only happen because ewe lambs had an ascending evolution of bodyweight and BMI, in the Villas Boas model of production, which provides an appropriate body development.

In addition, it is deduced that some females submitted to either progestogens or long-acting progesterone administration followed by biostimulation, display a multiplier effect in any group of young females and thus the cyclicity will be stimulated leading animals to puberty. As a consequence of the use of such strategy, ewe lambs younger than one year of age will be able to produce an offspring.

\section{References}

Bathaei, S., 1996. Breeding season and estrous activity of Iranian fat-tailed Mehraban ewes and ewe lambs. Small Ruminant Res.
22:13-23.

Bicudo, S.D., Sartori Filho, R., Curi, P.R., 1995. Distribution of body mass index (BMI Quetelet) according to the season and pregnancy status in Nellore cows. Proc. 3rd Brazilian Congr. on Animal Reproduction, Belo Horizonte, Brazil, 11:373 (abstr.).

Bielli, A., 2000. Influence of pre- and postpubertal grazing regimes on adult testicular morphology in extensively reared Corriedale rams. Anim. Reprod. Sci. 58:7386.

Chappell, G.L.M., 1993. Nutritional management of replacement sheep utilizing southern forages: a review. J. Anim. Sci. 71:3151-3154.

Cochran, W.G., Cox, G.M., 1976. Experimental Designs. John Wiley \& Sons, New York, NY, USA.

Evans, A.C.O., Duffy, P., Crosby, T.F., Hawken, P.A.R., Boland, M.P., Beard, A.P., 2004. Effect of ram exposure at the end of progestogen treatment on estrus synchronisation and fertility during the breeding season in ewes. Anim. Reprod. Sci. 12:131140.

Godfrey, R.W., Gray, M.L., Collins, J.R., 1997. A comparison two methods of oestrus synchronization of sheep in the tropic. Anim. Reprod. Sci. 47:99-106.

Martin, L.C., 1992. Genetic effects on beef heifer puberty and subsequent reproduction. J. Anim. Sci. 70:4006-4017.

Mellado, M., Olivas, R., Ruiz, F., 2000. Effect of buck stimulus on mature and pre-pubertal norgestomet-treated goats. Small Ruminant Res. 36:269-274.

Mobini, A., 2002. Theriogenology of sheep and goats. In: D.C. Pugh (ed.) Sheep and Goat Medicine, Saunders, Philadelphia, PA, USA, pp 129-186.

Moreno, J.S., Brunet, A. G., Bulnes, A.G., Villar, D., Sebastian, A.L., 1999. Attainment of Puberty in the European Mouflon "Ovis gmelini musimon" and the Domestic Manchega Ewe "Ovis aries". Reprod. Domest. Anim. 24:38-41.

Radostits, O.M., Leslie, K.E., Fetrow, J., 1994. Herd Health Food Animal Production Medicine 3rd ed. Saunders, Philadelphia, PA, USA.

Rawlings, N.C., Evans, A.C.O., Honaramooz, A., Bartelewski, P.M., 2003. Antral follicle growth and endocrine changes in prepubertal cattle, sheep and goats. Anim. Reprod. Sci. 78, 259-70.

Roman, J., Rock, M.G., Saucer, C.C., Elejalde,
D.A.G., Kloss, M.G., Grandson, R.A.0., 2007. Ingestive Behavior and ovine acting in pasture of annual azevém (Lolium multiflorum Scan.) with different forage masses. Rev. Bras. Zootecn. 36:780-788.

Rosa, H.J.D., Bryant, M.J., 2002. The 'ram effect' as a way of modifying the reproductive activity in the ewe. Small Ruminant Res. 45:1-16.

Sasa, A., Teston, D.C., Rodrigues, P.A., Coelho, L.A., Schalch, E., 2002. Plasmatic concentrations of Progesterone in ewe lambs in the Period of April to November in the State of São Paulo. Rev. Bras. Zootecn. 31:1150-1156.

Schillo, K.K., Halls, J.B., Hileman, S.M., 1992. Effects of Nutrition and Season on the Onset of Puberty in the Beef Heifer. J. Anim. Sci. 70:3994-4005.

Senger, P.L. 1997. Pathways to pregnancy and parturition. 1st ed., Mack Printing GroupScience Press, Ephrata, PA, USA.

Shabankareh, K.H., Habibizad, J., Turky, M., 2009. Corpus luteum function following single and double ovulation during estrous cycle in Sanjabi ewes. Anim. Reprod. Sci. 114:362-369.

Umberger, S.H., Jabbar, G., Lewis, G.S., 1994. Seasonally anovulatory ewes fail to respond to progestogen treatment in the absence of gonadotropin stimulation. Theriogenology 42:1329-1336.

Ungerfeld, R. 2003. Reproductive responses of anestrous ewes to the introduction of rams. Degree Diss., Swedish University of Agricultural Sciences, Uppsala, Sweden.

Ungerfeld, R., Suarez, G., Carbajal, B., Silva, L., Laca, M., Fosberg, M., Rubianes, E., 2003. Medroxyprogesterone priming and responses to the ram effect in Corriedale ewes during the nonbreeding season. Theriogenology 60:35-45.

Villarroel, A.B.S., Lima, L.E.S., Oliveira, S.M.P., Fernandes, A.A.0., 2006. Weight gain and carcass traits of Texel and Santa Inês crossbred lambs in a semi-intensive husbandry system. Cienc. Agrotec. 30:971-976.

Villas Bôas, A.S., Arrigoni, M.D.B., Silveira, A.C., Costa, C., 2003. Age to it weans her and handling to feed in lambs production. Rev. Bras. Zootecn. 32:1969-1980.

Zarco, L., Rodrigues, E.F., Angulo, M.R.B., Valencia, J., 1995. Female to female stimulation of ovarian activity in the ewe. Anim. Reprod. Sci. 39:251-258. 